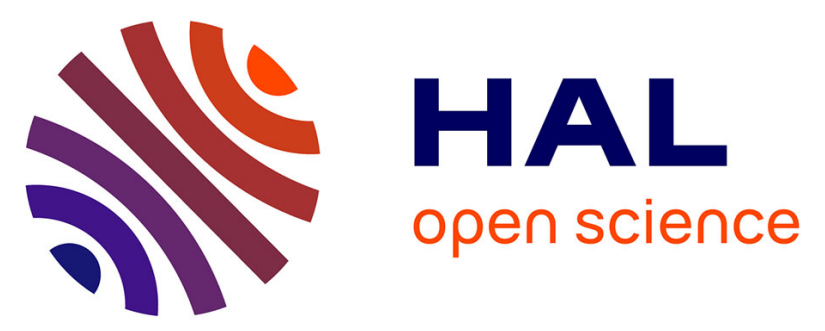

\title{
Investigating the Value Perception of Specific TRIZ Solutions Aimed to Reduce Product's Environmental Impact
}

Lorenzo Maccioni, Yuri Borgianni

\section{- To cite this version:}

Lorenzo Maccioni, Yuri Borgianni. Investigating the Value Perception of Specific TRIZ Solutions Aimed to Reduce Product's Environmental Impact. 19th International TRIZ Future Conference (TFC), Oct 2019, Marrakesh, Morocco. pp.282-294, 10.1007/978-3-030-32497-1_23 . hal-02905530

\author{
HAL Id: hal-02905530 \\ https://hal.inria.fr/hal-02905530
}

Submitted on 23 Jul 2020

HAL is a multi-disciplinary open access archive for the deposit and dissemination of scientific research documents, whether they are published or not. The documents may come from teaching and research institutions in France or abroad, or from public or private research centers.
L'archive ouverte pluridisciplinaire HAL, est destinée au dépôt et à la diffusion de documents scientifiques de niveau recherche, publiés ou non, émanant des établissements d'enseignement et de recherche français ou étrangers, des laboratoires publics ou privés.

\section{(c)(1)}

Distributed under a Creative Commons Attribution| 4.0 International License 


\title{
Investigating the value perception of specific TRIZ solutions aimed to reduce product's environmental impact
}

\author{
Lorenzo Maccioni ${ }^{10000-0002-2368-6821]}$ and Yuri Borgianni ${ }^{10000-0002-5284-4673]}$ \\ ${ }^{1}$ Faculty of Science and Technology, Free University of Bozen-Bolzano, 39100 Bolzano, Italy \\ lorenzo.maccioni@natec.unibz.it
}

\begin{abstract}
Understanding the impact of inventive solutions on consumers' value perception is essential to develop successful products. This applies particularly to sustainable solutions, which need to penetrate the market to pursue environmental objectives. This paper explores the value perception of three categories of TRIZ-oriented sustainable solutions, namely designs that have undergone dynamization, change of the physical state or the field exploited. Through an experimental study with 43 participants, supported by a specific questionnaire and biometric measures (eye tracking, skin conductance), self-assessments and unconscious behavioral aspects were gathered while a series of 18 product pictures was shown. Out of them, 9 products implement one of the above TRIZ-oriented principles and 9 constitute same-category products with a higher environmental impact. The results show that the different categories of TRIZ solutions give rise to diverse nuances of value perception. This outcome triggers further considerations concerning the ease of interpreting design modifications steered by TRIZ concepts and heuristics.
\end{abstract}

Keywords: Human Perception, Eco-Design, Eco-Innovation, TRIZ-oriented sustainable solutions, Biometric measures.

\section{Introduction}

Although TRIZ methodology supports the individuation of technical problems (i.e. what are the problems?) and provides frameworks to solve them (i.e. how to solve the problems?), many scholars argue that the contextualization of the problems (i.e. why should these problems be solved?) has to be entrusted to complementary methods [1, 2]. Therefore, especially when the problem solving process is set in a Business-to-Consumer product development context, TRIZ suffers from a limited understanding of human values, product meanings, and unspoken needs [3]. To this respect, many attempts to integrate human factors into TRIZ can be found in the literature.

Wang [4] developed a Kansei-TRIZ framework, where the design philosophy proposed by Nagamachi [5], aimed to consider the cognitive and emotional dimensions of 
designs, has been integrated with the 39 engineering parameters and the 40 inventive principles.

Borgianni et al. [6] developed a method able to take into account both the customers perceived benefits and the engineering resources exploited trough the combination of the Kano model [7] and specific TRIZ knowledge. The combination of Kano model and TRIZ can be found also in [8], where an integrated framework was proposed, and in [9], where a combination of Kano model and Su-Field Analysis was suggested.

In their review, Batemanazan et al. [2] highlight the pro and cons to combine usability criteria (to understand the user perspective and context) and TRIZ (to help the problem abstraction). In addition, the scholars stressed the importance to envision a holistic perception of products and criticized the products' characterizations solely based on a sum of the implemented functions. Filippi and Barattin [1] developed a framework to relate constructs of interactive design (i.e. principles, guidelines and heuristics aimed to improve the product's acceptance and reliability) with inventive principles. Lin and Luh [10] emphasized how TRIZ thinking should be enriched in a holistic view to support radical innovation through the human-centered value creation. In the same direction, Ávila et al. [11], exploring the combination of TRIZ and the User Centered Design approach, concluded that an inventive product cannot be successful if it does not create enough value for the consumers compared to alternative solutions.

Therefore, understanding how to create value for the consumer through inventive solutions (which include tangible and intangible elements) is the main way to innovate, and to achieve radical innovation [12]. This leads to the need to develop inventive solutions (exhibiting an evident technical improvement) that have a positive impact on human life through their use, acceptance and diffusion.

It is worth noting how the same challenges are shared by research in sustainable development $[13,14]$. Indeed, in order to outline sustainable development, designers are urged to develop eco-innovative products and services, i.e. solutions able to drastically reduce the environmental impact (compared to existing ones) and to increase people's quality of life $[15,16]$. Although the focus of many scholars was on developing and testing TRIZ-based tools and methods for achieving solutions with lower environmental impact, the literature offers a limited contribution for understanding how these TRIZ-Oriented Sustainable Solutions (TRIZ-OSSs) can be perceived, adopted and used. An experiment was conducted by the authors with the aim to study, among the others, the Consumer Value Perception (CVP) of TRIZ-OSSs [17]. The results of the experiment are used to provide a better understanding on the perception of TRIZ-OSSs.

The present paper is structured as follows. In Section 2, an overview of the relationship between TRIZ and eco-innovation is shown in order to clarify how TRIZ-OSSs can be obtained. In Section 3, the concept of CVP and the way adopted to measure it is explained. The method is illustrated in Section 4. Results are presented in Section 5. and discussed in Section 6. Conclusions are drawn in Section 7. 


\section{TRIZ and eco-innovation}

The application of many TRIZ tools and principles directly provide benefits for the environment [18]. Russo [19], exploring different eco-design methods, claimed that integrating TRIZ into eco-design leads to effective methods in both eco-improvement and eco-assessment perspectives. Bocken et al. [20] emphasized how the eco-TRIZ literature supports radical eco-improvements and provides many conceptual eco-assessment indicators.

Tyl et al. [15] stressed the remarkable contribution of TRIZ-based tools in eco-innovation process, especially in the ideation phase. In addition, the close relationship between TRIZ and eco-innovation was highlighted in a recent contribution [21], where more than 60 pertinent scientific works published in 2000-2018 were collected and analyzed. The overlapping between TRIZ and eco-design had already been noticed by Jones and Harrison at the very beginning of this century [22]. In their work, they compared the eco-compass headlines [23], i.e. mass intensity, energy intensity, extending service and function, health and environmental risk, resource conservation, and revalorization, with the 39 engineering parameters. Chang and Chen [24] developed a CAD software by integrating the same 39 parameters into the 7 major eco-efficiency elements identified during the World Business Council for Sustainable Development [25], i.e. material reduction, energy reduction, toxicity reduction, material retrieval, sustainable resources, product durability and product service. The same research team provided, for each of the 40 inventive principles, at least one successful eco-innovative product that implements it [26]. With the same aims of the previous authors, Cherifi et al. [27] developed a framework that supports the identification of the most suitable inventive principles to solve contradictions on specific eco-design parameters e.g. material consumption, energy consumption, releases, use of parameters, ownership of eco-design.

Inventive principles and engineering parameters were not the only TRIZ tools able to support eco-innovation. For example, the eternal struggle between technological and biological interest was dealt with in Bio-inspired TRIZ tools [28] and many other TRIZ concepts [29] e.g. biomimetic, ideality, function analysis and laws of evolution. Laws of evolution and evolution trends in an eco-innovation context have been explored in various papers $[19,30,31]$.

The usefulness and the applicability of the evolution trends in eco-design was discussed in [31]. Russo [19], pivoting on the concept of ideality, resources and laws of evolution, developed 8 guidelines aimed at driving eco-design towards innovation. Based on the results of this work, Russo et al. [30] developed an evaluation method to assess a solution and to support the design towards the ideal solution (also exploiting the concept of Energy, Material, Signal [32] and standard solutions). This method was fine-tuned in SMEs [33] and subsequently, an advanced CAD system was created [34].

However, the integration and the application of TRIZ in the eco-innovation processes still presents some limitations. For instance, most of TRIZ approaches require a good level of expertise, and therefore, an effective application of TRIZ entails time and training to be successfully applied by novices in the TRIZ field [35]. In order to overcome these limitations, Russo et al. [36] proposed guidelines for non-expert users, col- 
lected in a framework called iTree; in addition, an advanced version thereof was developed in an online CAD tool [37]. Moreover, as emphasized in the introduction, specific TRIZ methods are limited to work only under well-defined boundaries [35].

Although this section stress the goal to link TRIZ with eco-innovation and the introduction highlights some attempts that link TRIZ with human-related issues, in the literature, only few contributions can be found that try to link these tree areas (TRIZ, ecoinnovation and human-related issues). The main attempt to expand the ECO-TRIZ knowledge towards human-related issues are reported in the followings.

D'Anna and Cascini [38] developed a method integrating the humankind into TRIZ for identifying needs through the combination of System Operator and Maslow's Hierarchy of needs [39]. With the aim of achieving sustainable objective, the voice of the consumer was taken into consideration by the combination of TRIZ, Eco-Quality-Function-Deployment and Analytical Hierarchy Process in [40]. Recently, a Kansei ECOTRIZ technique was developed [41], where Kansei Engineering has been juxtaposed with the 39 engineering parameters and the 7 Eco-efficiency elements proposed in a previous study [24].

Therefore, this paper aims to expand the ECO-TRIZ knowledge towards studying the CVP of specific TRIZ-OSSs.

\section{Consumer Value Perception}

The CVP drives the consumer behavior in a decision-making context, affects their preferences and purchase intention, and, consequently, the adoption and the success of the solution [42]. Woodal [43] conceptualized CVP as a comparison between benefits, in terms of advantages that the ownership (or the use) of the solution provides to the consumer, and sacrifices, in terms of resources that the consumer has to spend for the ownership (or the use) of the solution. Although this definition is similar to the TRIZ concept of Ideal Final Result, it not only includes the utilitarian/functional dimension but also a hedonic/emotional one. In addition, Holbrook [44] emphasized how the CVP is not a property of the solution itself but it is an experiential characteristic of the interaction between the consumer and the product. Then, the proper way to study the CVP is to capture consumers' perception about functionalities, feelings, experiences, emotions and behaviors during an interaction with the solution (or its representation).

The perception of utilitarian/functional dimensions is usually investigated trough surveys. However, it is claimed that the exclusive use of self-assessment methods might fail to capture human factors in a reliable way, especially when sustainability-related themes are involved [45]. To overcome these limitations, the exploitation of biometric instruments are increasingly diffused in experimental design research [46], especially Eye-Tracking (ET) technologies and Galvanic Skin Response (GSR) meters. The ET allows recording the ocular behavior by understanding what a participant is looking at, for how long, with which observation strategy, how often s/he blinks and how the pupils' size changes. These data can be interpreted as attention, interest, involvement, curiosity, cognitive load other psychological and behavioral terms. GSR meters meas- 
ure skin conductance and markedly the micro-sweat changes that are ascribable to emotional arousal. The combination of surveys, for studying the utilitarian/functional dimensions, with biometric instruments, for exploring the unconscious behavioral and emotional reactions, is the last frontier of the study of the CVP [17].

\section{$4 \quad$ Materials and Method}

The goal of this paper is to understand how the implementation of TRIZ-OSSs affects the CVP. In order to pursue this goal, the following steps were performed.

1. Three common TRIZ-OSSs, easily identifiable in everyday products, were selected. Pictures of these products in a baseline version (presenting specific environmental issues) and in the TRIZ-OSSs version (presenting an eco-improvement) were collected (Section 4.1).

2. The pictures of each product were shown singularly to 43 participants (individually) in a PC screen. The participants were asked to evaluate each picture by filling in a 5-point Likert questionnaire, according to their perception of the products. Meanwhile, their visual approach and behavior were monitored through an ET and their level of emotional arousal was captured by a GSR (Section 4.2). This is part of a larger study described in [17].

3. The data collected were statistically elaborated in order to highlight differences in CVP characteristics and to understand if these are statistically influenced by the type of TRIZ-OSS (Section 4.3)

\subsection{Characterization of the stimuli}

Nowadays, the excessive use of resources, the amount of wasted packaging and the toxicity of energy systems are environmental problems designers are asked to solve. TRIZ offers many strategies to deal with these problems and, since the proposed experimental procedure (Section 4.2) is time-consuming, this paper explores a subset of these strategies. Therefore, among the most common implemented TRIZ strategies, the authors focused on the following ones, which were empirically identified as very diffused in innovative product design.

- Dynamization, which saves material (allowing the replacement of worn components only), space and energy resources (improving the adaptability of the product during various phases of its life)

- Change the product's Substance (solid, liquid, gas), often allows reducing the environmental impact of its packaging or of its transportation

- Change a Field that performs a function (mechanical, chemical, electromagnetic), which often allows reducing the related toxic emissions.

For these reasons, for each of the three above-mentioned TRIZ-OSSs, three pairs of everyday products were collected ( 3 TRIZ-OSSs and the 3 corresponding baseline products). 
- Dynamization: disposable razors vs. razors with interchangeable blades, common toothbrushes vs. toothbrushes with interchangeable bristles, common water bottles vs. space-saving water bottles.

- Substance: liquid laundry detergent in a plastic packaging vs. washing powder in a cardboard packaging, a liquid shampoo in a plastic container vs. a solid shampoo in a paper container, couches vs inflatable couches.

- Field: battery torches vs. hand-powered torches, gasoline cars vs. electric cars, gas cookers vs. induction cookers.

A summary is shown in Figure 1.

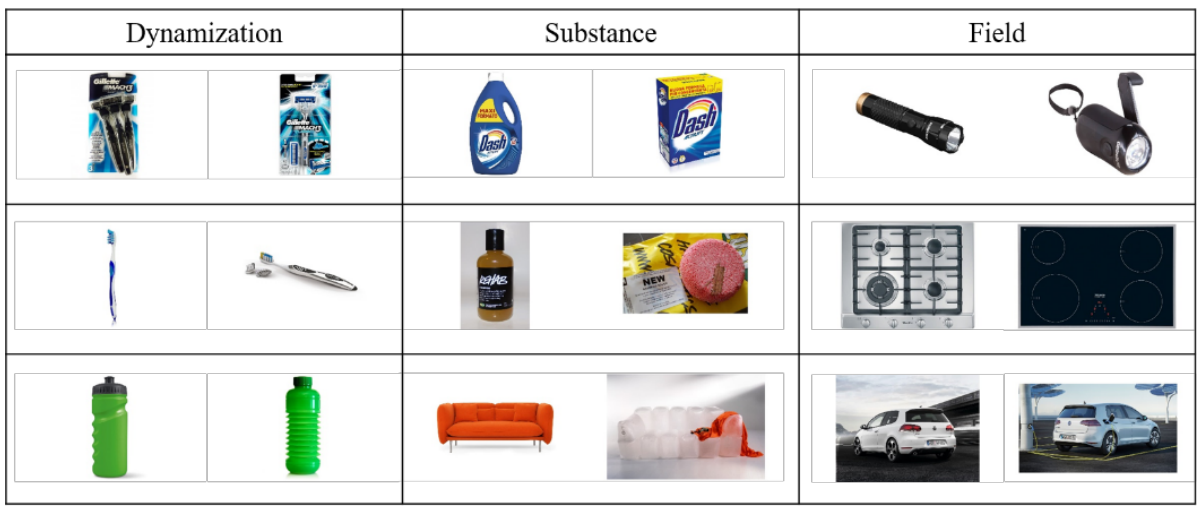

Fig. 1. The products are presented in pairs - the baseline version on the left, the TRIZ-OSS on the right. Product pairs implementing the same TRIZ-OSS are grouped in the same column

\subsection{Procedure}

Forty-three volunteer participants were involved in this experiment and all product pictures were shown randomly in two sessions at least two days apart. All the participants were students, lecturers and administrators of research institutions in South Tyrol, Italy. Their sensitivity to sustainable themes was monitored through a preliminary questionnaire, which was a primary research goal explored in [17].

In addition to the 18 products illustrated in the previous subsection, other 22 product's images were selected with similar criteria, and shown in the same way for other purposes [17].

The baseline products and the TRIZ-OSS alternatives were equally distributed between the two sessions and the products of the same pair have never been shown in the same session. The participants were informed that the aim of the experiment was to evaluate products and that biometric instruments would have been used. They were unaware of the type of products to be evaluated, the actual goal of the experiment, as well sustainability-related terms have never emerged during the experiment.

While the image of a product was shown on a PC screen, the participants were invited to observe it, to fill in a questionnaire (in which their level of agreement with statements associated with the variables summarized in Table 1 was gathered) and to estimate the product's price. In the meantime, they were wearing a GSR sensor, in the 
non-writing hand, and a remote ET, arranged at the bottom of the screen, was recording their ocular behavior. In this way, the functional dimensions of CVP were investigated trough a self-assessment questionnaire, while the unconscious emotional and behavioral dimensions were studied trough the afore-mentioned biometric instruments. The whole sample of collected data is available in [17].

Table 1.Variables explored through a 5-point Likert scale questionnaire.

\begin{tabular}{ll}
\hline \multicolumn{1}{c}{ Variables } & $\begin{array}{l}\text { Meaning } \\
\text { Level of agreement of the participant in affirming that: }\end{array}$ \\
\hline Knowledge & $\begin{array}{l}\text { The participant knows the specific product, they use it, they have bought } \\
\text { it in the past and they know similar products. } \\
\text { The aim of the product is relevant to their daily life, they are interested in } \\
\text { this kind of products and they can benefit from it. } \\
\text { Thterest }\end{array}$ \\
The participant believes that it the product is of high quality and is able to \\
meet their expectations.
\end{tabular}

\subsection{Data elaboration}

The raw data collected through biometric instruments were elaborated by a specific MATLAB routine in order to obtain indicators related to the interaction between each participant with each products. The biometric indicators were combined with the indicators extracted through the questionnaire. A series of bivariate Spearman correlations, involving the whole samples of indicators was performed. When two indicators showed correlations greater than 0.8 , one of the two was discarded to facilitate following statistical processes. In this way, the independent indicators who passed the Spearman test were 35 out of the initial 93 ones. In order to reduce the complexity of the phenomenon to be studied, a Principal Component Analysis was then performed on these 35 variables. The "principal" function in the statistical software R was used for the PCA. Keeping factors with eigenvalues higher than 1 resulted in obtaining 10 principal components (PCs) explaining $68 \%$ of the variability of the observed phenomenon. An interpretation of these 10 PCs was given in [17] and it is summarized in Table 2.

Data related to products implementing a TRIZ-OSS (including the relative baseline products) were extrapolated from the whole dataset. Subsequently, this data was subdivided between Dynamization, Substance, Field and the amount of valid observations (in the PCs coordinates) were 204, 202 and 196 respectively. 
The implementation of a given category of TRIZ-OSS has been considered as a dummy variable in the products pair ( 1 if the product implements the TRIZ-OSS, 0 if the product is the alternative baseline). Therefore, two different kind of regressions were carried out through R software.

1. In order to study the overall phenomenon, linear regressions between every category of TRIZ-OSSs (as independent variables) and every PCs (as dependent variables) were carried out.

2. In order to provide results that can be simply interpreted on CVP perspective, ordinal logistic regressions between every category of TRIZ-OSSs (as independent variables) and the answers to the 5-scale questionnaire (as dependent variables).

Table 2. Interpretation of the PCs emerged by the experiment.

\begin{tabular}{|c|c|}
\hline $\begin{array}{l}\text { Principal } \\
\text { Components }\end{array}$ & Interpretation \\
\hline $\begin{array}{l}\text { Consciously Approaching } \\
\text { the Task (CAT) }\end{array}$ & $\begin{array}{l}\text { It is related to those processes occurring while consciously } \\
\text { approaching the task (looking at the screen many times, fast } \\
\text { answers etc.). }\end{array}$ \\
\hline Level of Arousal (LA) & It defines the emotional involvement. \\
\hline Implicit Task Effort (ITE) & $\begin{array}{l}\text { It describes implicit task effort, being related to the activation } \\
\text { of the autonomous nervous system combined with long time } \\
\text { to complete the evaluation task. }\end{array}$ \\
\hline Information Foraging (IF) & It describes the tendency to search many information. \\
\hline Innovative Value (IV) & $\begin{array}{l}\text { Beyond quality-related aspects, this component is character- } \\
\text { ized by the perceived presence of novel or creative aspects. }\end{array}$ \\
\hline Price Overestimation (PO) & It describes the tendency to overestimate the product's price. \\
\hline $\begin{array}{l}\text { Voluntary Wide Exploration } \\
\text { (VWE) }\end{array}$ & $\begin{array}{l}\text { The variables explain the typical behavior occurring when } \\
\text { eyes were pointing to different targets. }\end{array}$ \\
\hline Pupil Dilation (PD) & $\begin{array}{l}\text { It is deemed as a descriptor of phenomena involving large pu- } \\
\text { pil dilation. }\end{array}$ \\
\hline $\begin{array}{l}\text { Curiosity and Exploration } \\
\text { (CE) }\end{array}$ & $\begin{array}{l}\text { Curiosity- and exploration-related factors appear as determi- } \\
\text { nants (long eyes movements and large dimension of pupils). }\end{array}$ \\
\hline Ordinary Value (OV) & $\begin{array}{l}\text { Knowledge and interest dimensions are fundamental dimen- } \\
\text { sions for this component. }\end{array}$ \\
\hline
\end{tabular}

\section{Results}

The influence of the TRIZ-OSSs on PCs is shown in the upper part of Table 3, while the influence of the TRIZ-OSSs on the variables investigated through the questionnaire is shown in the bottom part of Table 3. For every relationship, the regression coefficient and the $\mathrm{p}$-value are reported in the Table. Relationships with $\mathrm{p}$-value higher than 0.1 are written in light gray as considered not statistically significant, while the relationships characterized by $0.1>\mathrm{p}$-value $>0.05$ are indicated with (.) after the coefficient. 
The regression coefficient can be read as metric of the specific TRIZ-OSS's power to positively (negatively) affect the dependent variable if it is positive (negative).

Table 3. Results of the linear regressions between TRIZ-OSSs and PCs, and ordinal logistic regressions between TRIZ-OSSs and questionnaire variables

\begin{tabular}{|c|c|c|c|c|c|c|}
\hline \multirow{2}{*}{$\frac{\text { Independent Variables } \rightarrow}{\text { Depenent Variables } \downarrow}$} & \multicolumn{2}{|c|}{ Dynamization } & \multicolumn{2}{|c|}{ Substance } & \multicolumn{2}{|c|}{ Field } \\
\hline & Coeff. & p-value & Coeff. & p-value & Coeff. & p-value \\
\hline CAT & 0.255 & 0.047 & 0.101 & 0.464 & -0.053 & 0.703 \\
\hline LA & -0.037 & 0.765 & -0.065 & 0.661 & -0.062 & 0.659 \\
\hline ITE & 0.086 & 0.608 & 0.557 & 0.000 & 0.007 & 0.962 \\
\hline IF & -0.054 & 0.674 & -0.040 & 0.753 & 0.144 & 0.391 \\
\hline IV & 0.256 & 0.050 & 0.327 & 0.012 & 0.335 & 0.023 \\
\hline $\mathrm{PO}$ & -0.105 & 0.425 & 0.077 & 0.550 & -0.072 & 0.656 \\
\hline VWE & -0.391 & 0.001 & 0.109 & 0.265 & -0.035 & 0.799 \\
\hline PD & 0.782 & 0.000 & -0.200 & 0.093 & 0.460 & 0.000 \\
\hline $\mathrm{CE}$ & 0.545 & 0.000 & 0.320 & 0.018 & -0.115 & 0.296 \\
\hline OV & -0.437 & 0.000 & -0.923 & 0.000 & -0.647 & 0.000 \\
\hline Knowledge & -0.544 & 0.001 & -0.749 & 0.000 & -0.647 & 0.000 \\
\hline Interest & -0.011 & 0.943 & -0.472 & 0.003 & 0.173 & 0.274 \\
\hline Quality & 0.565 & 0.001 & -0.736 & 0.000 & -0.125 & 0.447 \\
\hline Advantages & 0.826 & 0.000 & -0.148 & 0.349 & 0.737 & 0.000 \\
\hline Absence of Disadvantages & -0.216 & 0.167 & -0.682 & 0.000 & -0.445 & 0.005 \\
\hline Preference & 0.498 & 0.002 & -0.402 & 0.011 & 0.164 & 0.293 \\
\hline Novelty Creativity & 1.568 & 0.000 & 0.661 & 0.000 & 1.334 & 0.000 \\
\hline Willingness_to_Pay & 0.676 & 0.000 & -0.291 & 0.065 & 0.337 & 0.032 \\
\hline
\end{tabular}

\section{Discussions}

All the TRIZ-OSSs showed a significantly increased IV and diminished OV. The participants revealed a low knowledge of these TRIZ-OSSs and changing Substance displays the lowest acceptance level. Indeed, although TRIZ-OSSs implementing change of Substance are considered more new and creative than baseline solutions, these lead to a negative perception of quality, a low level of interest and a negative preference. In addition, this is followed by a negative Willingness to Pay (WTP), by a perception of disadvantages and a not clear perception of advantages. Moreover, the low level of affordances was highlighted by the significant positive effect on ITE and negative on PD. This result suggests that solutions implementing this TRIZ-OSS may 
not be competitive with the baseline one. However, these solutions could be successful in specific market sectors targeted to peculiar consumers.

TRIZ-OSSs implementing change of Field are perceived undoubtedly new and creative but the advantages, clearly perceived by participants, are counterbalanced by disadvantages noticed in the solutions. In addition, a positive WTP has emerged while a significant preference, interest and perception of quality have not. These results could mean that solutions changing Field are perceived innovative but not sufficiently mature. Therefore, further efforts should be made to reduce their real or perceived disadvantages.

TRIZ-OSSs implementing Dynamization showed a clear perception of quality, advantages and preference enhanced by novelty and creativity that lead to a positive WTP. The PCs related with biometrics measures indicate how the evaluation process takes place through a careful, curious and meticulous observation of the solutions. These solutions seems to be the most valued by the participants, and a possible explanation can be found in the ability of the products to meet participants' expectations. Indeed, the TRIZ-OSSs offer comparable (or better) performances compared with the baseline ones and provide additional benefits that can be directly exploited during the products' use. In particular, they provide useful functions for both the user and the environment without perceivably increasing costs and/or harmful effects.

Furthermore, by comparing the TRIZ-OSSs investigated, it is possible to note differences in the way solutions provide benefits to consumers. Indeed, while all the solutions provide direct benefits for the environment, only the Dynamization provides direct benefits for the user e.g. the possibility of replacing only the worn blades or bristles instead of buying a completely new product. In the used case studies, this is accompanied by a change in business model. The effects brought on by more dynamic solutions are worth investigating further; in particular, it should be studied whether these remarks emerge because of the specific products leveraged in the experiment or have general validity.

\section{Conclusions}

The paper provides an overview of the literature involving humankind and/or ecological issues in the TRIZ methodologies. It highlights how the contextual analysis of both perspectives is limited. Accordingly, the authors performed an experimental study aimed with a dual purpose: to provide a methodological framework to investigate the CVP from functional, hedonic and behavioral perspectives and to capture differences in CVP between baseline products and the alternative TRIZ-OSSs, i.e. potentially inspired by Dynamization, Substance and Field. Different TRIZ strategies resulted in marked differences in terms of CVP.

Indeed, the results showed how the change of Substance leads to decrease the solutions' acceptance while improving the environmental performances, which limits the competitive advantages compared with baselines solutions. Innovative advantages are per- 
ceived in the solutions performing functions through a different Field, but the perception of disadvantages could be the main barrier to their preference and adoption. Solutions implementing Dynamization give rise to better feedback from participants in many dimensions that are fundamental for successful innovation.

Two considerations emerge from these results. Firstly, the preferred TRIZ-OSSs combine environmental and humans' benefits with no performance drop, delivering new valuable attributes. Secondly, the TRIZ-OSSs with lower acceptance levels are more suitable for radical product changes while the most appreciated ones are more suitable for incremental innovations.

These results enrich the ECO-TRIZ knowledge by providing a general perspective on the perception of products implementing specific strategies. This information increases the designer's awareness of possible risks related to the radical change of a solution and the need to involve potential consumers in order to be able to develop acceptable solutions with, consequently, enhanced success chances. This newly generated knowledge is, however, constrained by the limited number of TRIZ-OSSs; this represents a trigger for future research.

\section{References}

1. Filippi, S., Barattin, D.: Exploiting TRIZ tools in interaction design. Procedia engineering, 131, 71-85 (2015)

2. Batemanazan, V., Jaafar, A., Kadir, R. A., Nayan, N. M.: Improving Usability with TRIZ: A Review. In International Visual Informatics Conference. pp. 625-635. Springer, Cham. (2017)

3. Van Pelt, A., Hey, J.: Using TRIZ and human-centered design for consumer product development. Procedia Engineering, 9, 688-693 (2011)

4. Wang, C. H.: Combining rough set theory with fuzzy cognitive pairwise rating to construct a novel framework for developing multi-functional tablets. Journal of Engineering Design, 29(8-9), 430-448 (2018)

5. Nagamachi, M.: Kansei engineering: a new ergonomic consumer-oriented technology for product development. International Journal of industrial ergonomics, 15(1), 3-11 (1995)

6. Borgianni, Y., Cascini, G., Rotini, F.: Process value analysis for business process reengineering. Proceedings of the Institution of Mechanical Engineers, Part B: Journal of Engineering Manufacture, 224(2), 305-327 (2010)

7. Kano, N.: Attractive quality and must-be quality. Hinshitsu Quality, The Journal of Japanese Society for Quality Control, 14, 39-48 (1984)

8. Chen, L. S., Hsu, C. C., Chang, P. C.: Developing a TRIZ-Kano model for creating attractive quality. In 2008 4th International Conference on Wireless Communications, Networking and Mobile Computing. pp. 1-6. IEEE. (2008)

9. Wu, C. T., Shao, M. H., Huang, C. L., Chen, C. H., Pan, T. S.: A Kano-Based Evaluation Model for Extensive Innovation Procedure. In 2013 Second International Conference on Robot, Vision and Signal Processing. pp. 178-181. IEEE. (2013) 
10. Lin, C. C., Luh, D. B. A vision-oriented approach for innovative product design. Advanced engineering informatics, 23(2), 191-200 (2009)

11. Ávila, J., González, S., Borja, V., Espinosa, A.: Using TRIZ Tools at Early Stages of a User Centered Design Process. In ASME 2013 International Mechanical Engineering Congress and Exposition. pp. V012T13A038-V012T13A038. American Society of Mechanical Engineers (2013)

12. Toivonen, T., Siitonen, J.: Value stream analysis for complex processes and systems. Procedia CIRP, 39, 9-15 (2016)

13. Vezzoli, C., Manzini, E.: Design for environmental sustainability. London. Springer. (2008)

14. Navas, H. V.: Radical and Systematic Eco-innovation with TRIZ Methodology. In EcoInnovation and the Development of Business Models. pp. 81-95. Springer, Cham. (2014).

15. Tyl, B., Legardeur, J., Millet, D., Vallet, F.: A comparative study of ideation mechanisms used in eco-innovation tools. Journal of Engineering Design, 25(10-12), 325-345 (2014)

16. D'Anna, W., Cascini, G.: Adding quality of life to design for Eco-Efficiency. Journal of Cleaner Production, 112, 3211-3221 (2016)

17. Maccioni, L., Borgianni, Y., Basso, D.: Value Perception of Green Products: An Exploratory Study Combining Conscious Answers and Unconscious Behavioral Aspects. Sustainability, 11, 1226 (2019)

18. Russo, D., Serafini, M., Rizzi, C.: Is TRIZ an Ecodesign Method?. In International Conference on Sustainable Design and Manufacturing. pp. 525-535. Springer, Cham. (2016)

19. Russo, D.: TRIZ-driven eco-design and Innovation. In ICORD 09: Proceedings of the 2nd International Conference on Research into Design, Bangalore, India. pp. 105-112. Design Society. Glasgow. (2009)

20. Bocken, N. M. P., Allwood, J. M., Willey, A. R., King, J. M. H.: Development of an ecoideation tool to identify stepwise greenhouse gas emissions reduction options for consumer goods. Journal of Cleaner Production, 19(12), 1279-1287 (2011)

21. Livotov, P., Sekaran, A. P. C., Law, R., Reay, D., Sarsenova, A., Sayyareh, S.: Ecoinnovation in process engineering: Contradictions, inventive principles and methods. Thermal Science and Engineering Progress, 9, 52-65 (2019)

22. Jones, E., Harrison, D.: Investigating the use of TRIZ in Eco-innovation, in TRIZCON2000 conference proceedings, Altshuller Institute, USA, (2000)

23. Fussler, C., James, P.: Eco-innovation: a breakthrough discipline for innovation and sustainability. Pitman: London. (1996)

24. Chang, H. T., Chen, J. L.: The conflict-problem-solving CAD software integrating TRIZ into eco-innovation. Advances in engineering software, 35(8-9), 553-566 (2004)

25. DeSimone, L. D., Popoff, F.: Eco-efficiency: the business link to sustainable development. MIT press. (2000)

26. Chang, H. T., Chen, J. L., Tainan, T.: Eco-innovative examples for 40 TRIZ inventive principles. The TRIZ Journal, 1-16 (2003)

27. Cherifi, A., Dubois, M., Gardoni, M., Tairi, A.: Methodology for innovative eco-design based on TRIZ. International Journal on Interactive Design and Manufacturing (IJIDeM), 9(3), 167-175 (2015) 
28. Bogatyrev, N., Bogatyreva, O.: BioTRIZ: a win-win methodology for eco-innovation. In Eco-innovation and the Development of Business Models. pp. 297-314. Springer, Cham. (2014)

29. Chen, J. L., Yang, Y. C.:Eco-innovation by integrating biomimetic with TRIZ ideality and evolution rules. In Glocalized Solutions for Sustainability in Manufacturing. pp. 101106. Springer, Berlin, Heidelberg. (2011)

30. Russo, D., Regazzoni, D., Montecchi, T.: Eco-design with TRIZ laws of evolution. Procedia engineering, 9, 311-322 (2011)

31. Chulvi, V., Vidal, R. Usefulness of evolution lines in eco-design. Procedia engineering, 9, 135-144 (2011)

32. Pahl, G., Beitz, W., Feldhusen, J., Grote, K. H.: Engineering design: a systematic approach. Springer, London (2007)

33. Russo, D., Schöfer, M., Bersano, G.: Supporting ECO-innovation in SMEs by TRIZ Ecoguidelines. Procedia engineering, 131, 831-839 (2015)

34. Russo, D., Serafini, M., Rizzi, C.: TRIZ based computer aided LCA for Ecodesign. Computer-Aided Design and Applications, 13(6), 816-826 (2016)

35. Tyl, B., Legardeur, J., Millet, D., Falchi, A., Ranvier, B.: A new approach for the development of a creative method to stimulate responsible innovation. In Global product development. pp. 93-104. Springer, Berlin, Heidelberg. (2011)

36. Russo, D., Rizzi, C., Montelisciani, G.: Inventive guidelines for a TRIZ-based eco-design matrix. Journal of Cleaner Production, 76, 95-105 (2014)

37. Russo, D., Rizzi, C., Spreafico, C.: How to Build Guidelines for Eco-Improvement. In International Conference on Sustainable Design and Manufacturing. pp. 879-887. Springer, Cham. (2017)

38. D'Anna, W., Cascini, G.: Supporting sustainable innovation through TRIZ system thinking. Procedia Engineering, 9, 145-156 (2011)

39. Maslow, A. H.: A theory of human motivation. Psychological review, 50(4), 370 (1943)

40. Vinodh, S., Kamala, V., Jayakrishna, K.: Integration of ECQFD, TRIZ, and AHP for innovative and sustainable product development. Applied Mathematical Modelling, 38(11-12), 2758-2770 (2014)

41. Chen, H. C.: Green Innovation Design Model of Kansei Engineering. In International Conference on Kansei Engineering \& Emotion Research. pp. 267-276. Springer, Singapore. (2018)

42. Swait, J., Sweeney, J. C.: Perceived value and its impact on choice behavior in a retail setting. Journal of Retailing and Consumer Services, 7(2), 77-88 (2000)

43. Woodall, T.: Conceptualising 'value for the customer': An attributional, structural and dispositional analysis. Academy of marketing science review, 12, 1-42 (2003)

44. Holbrook, M. B.: Consumer value: a framework for analysis and research. Psychology Press London, UK (1999)

45. Tseng, S. C., Hung, S. W.: A framework identifying the gaps between customers' expectations and their perceptions in green products. Journal of Cleaner Production, 59, 174184 (2013)

46. Lohmeyer, Q., Meboldt, M.: The Integration of Quantitative Biometric Measures and Experimental Design Research. In Experimental Design Research (pp. 97-112). Springer, Cham (2016) 